\title{
JVR as a Primary Journal dor Vascular Scientists
}

\begin{tabular}{|l|l|l|}
\hline M.J. & Michael J. & Mulvany \\
\hline G.K. & Gary K. & Owens \\
\hline
\end{tabular}

Unlike most journals in the vascular field, Journal of Vascular Research is not associated with any scientific society, and the editorial policy is dictated alone by the aim of increasing the scientific quality of its articles. This policy has, we believe, been rather successful and over the past few years, the number of submissions to the Journal has increased substantially, as has the quality of submissions. The Journal is well cited and, judging by the submissions, is now an attractive medium for leading vascular scientists.

The Journal is thus established, but it is at present limited in its ability to grow by financial circumstances, since the present 500 library subscriptions are insufficient to allow the publishers S. Karger to print more pages. As we all know, libraries are reluctant to take on new subscriptions, which means that the financial situation can only be improved by increasing the number of personal subscriptions. To achieve this, a major change in the subscriptions policy of the Journal of Vascular Research has been instituted. The price of personal subscriptions has been drastically reduced, and will now cost USD 72 (+ postage). At this price, we believe that it becomes realistic for scientists in this fast-growing field to have their own copy.

Other changes are also being made with the addition of two new sections: a Calendar section, listing details of meetings having particular interest for vascular scientists, and a general correspondence section, in which items of interest for readers can be put forward and discussed.

As Editors, we will continue to serve what we perceive to be the interests of vascular science: the publishing of high-quality articles. We hope that with these changes you too will be able to support these aims, by supporting the Journal of Vascular Research not only as a reader and contributor, but also as a personal subscriber. In this way JVR will truly be able to achieve its aim of being a leading journal in the field of vascular science.

\section{KAHGER}

E-Mail karger@karger.ch Fax + 41/613061234 http://www.karger.ch

(C) 1996 S. KargerAG, Basel

265 